\title{
Rapid Processing of Cultured Cells for LR White Embedding
}

\author{
Gang Ning and Paula Traktman
}

Department of Microbiology and Molecular Genetics, Medical College of Wisconsin, 8701 Watertown Plank Road, Milwaukee, WI 53226

LR White resin has been widely used for immunoelectron microscopy since it was first introduced two decades ago [1]. Its properties of processing at room temperature, fast infiltration, high water miscibility, and low toxicity make it superior to other resins used for post-embedding immunocytochemistry. However, in order to be processed as tissue blocks, cultured cells have to be enrobed in agar $[2,3]$ before undergoing a prolonged dehydration and infiltration prior to being embedded into LR White. This extended processing results in substantial extraction of cellular components and compromised morphology. Additionally, the cells embedded in LR White are transparent, so it is not easy to section through an area with a large number of the cells. In our present work, we found that this processing can be shortened to less than 60 min and the sample blocks can be ready for microtomy over night with improved morphology.

Monolayer culture of cells were fixed with $4 \%$ paraformaldehyde and $0.1 \%$ glutaraldehyde in PBS or $50 \mathrm{mM}$ HEPES supplemented with $10 \mathrm{mM} \mathrm{CaCl}_{2}, \mathrm{pH} 7.4$ at room temperature for $30 \mathrm{~min}$. The culture dishes were then moved to ice and the cells were scraped off and sedimented in a microcentrifuge tube at $4^{\circ} \mathrm{C}, 300 \mathrm{~g}$ for $10 \mathrm{~min}$. The cells were further fixed with a fresh ice-cold fixative for $30 \mathrm{~min}$. After removing the fixative, $3 \mu \mathrm{L}$ of concentrated cells from the bottom of the tube was blotted onto a piece of $4 \times 8 \mathrm{~mm}$ kimwipes tissue paper, which was then folded into $2 \times 4$ $\mathrm{mm}$ and processed, as follows, on ice. It was rinsed briefly with buffer, dehydrated for $3 \mathrm{~min}$ in $50 \%, 70 \%$, and twice in 100\% ethanol, infiltrated in three changes of pure LR White for $10 \mathrm{~min}$ each, and then embedded in LR White in gelatin capsules and cured at $57^{\circ} \mathrm{C}$ overnight (16 hrs).

This method allowed us to use a very small amount of sample to obtain a concentrated preparation of cells in a small section area (Fig. 1). The cells were intact, and intracellular organelles such as mitochondria, endoplasmic reticulum, granules, and vesicles had distinct membranous boundaries (Fig. 1\&2); Cells infected with vaccinia virus showed well preserved virion membrane structure and cytoskeletal networks (Fig. 3); immunogold labeling to detect specific proteins was clear and efficient (Fig. 4).

\section{References}

[1] G. R. Newman et al. J. Microsc. 127 (1982) RP5.

[2] A. B. Maunsbach et al, Biomedical Electron Microscopy Academic Press, San Diego, 1999.

[3] G. R. Newman and J. A. Hobot, J. Histochem Cytochem 35 (1987) 971.

Fig. 1. Rabbit corneal epithelia cells showing a group of cells in good morphdogy $x 4,000$.

Fig. 2. Chinese hamster ovary cells showing well preserved intracellular organelles $x 6,500$. Fig. 3. BSX-40 cells infected with vaccinia virus showing intracellular virions and adjacent vesicles and cytoskeletal network x 55,000

Fig. 4. Immunogold labeled actin at basolateral portion of BSX-40 cells infected with vaccinia virus $\mathrm{x} 18,000$. 


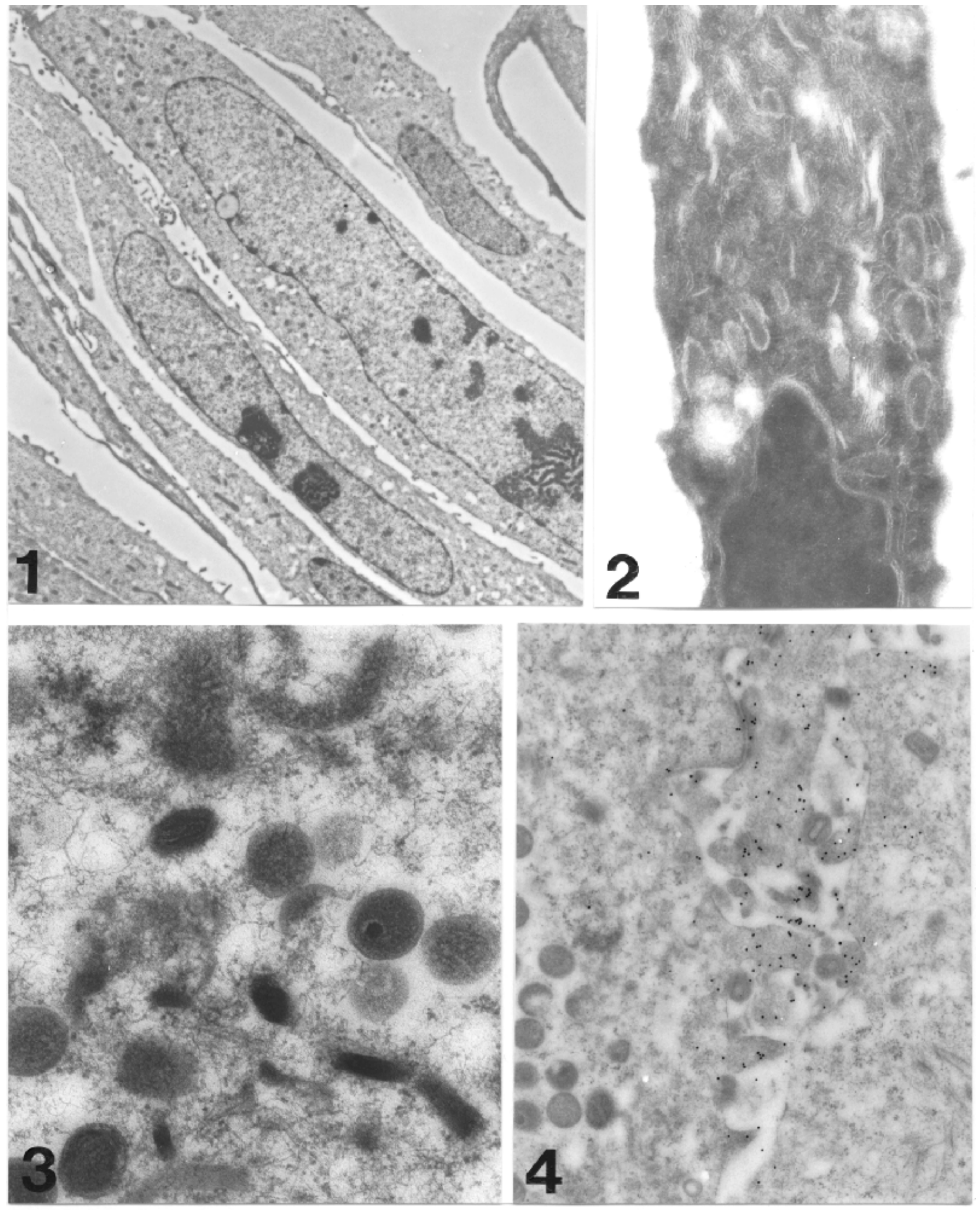

